\title{
Folic acid and its metabolites modulate IGF-I receptor gene expression in colon cancer cells in a p53-dependent manner
}

\author{
Z Attias, $H$ Werner and N Vaisman ${ }^{1}$
}

Department of Human Molecular Genetics and Biochemistry, Sackler School of Medicine, Tel Aviv University, Tel Aviv 69978, Israel

${ }^{1}$ Unit on Clinical Nutrition, Tel Aviv Sourasky Medical Center, Tel Aviv, Israel

(Requests for offprints should be addressed to H Werner; Email: hwerner@post.tau.ac.il)

\begin{abstract}
The insulin-like growth factor-I receptor (IGF-IR) has an important role in colorectal cancer development and progression. IGF-IR displays a potent anti-apoptotic activity and is overexpressed in primary tumors and colon cancer-derived cell lines. Folic acid, a member of the vitamin B family, is a chemopreventive agent whose deficiency has been linked to an enhanced colon cancer risk. The present study was aimed at testing the hypothesis that part of the modulatory effect of folic acid on malignant transformation may be attributed to its ability to regulate IGF-IR gene expression. Regulation of IGF-IR gene expression by folic acid was assessed using western blots, RT-PCR, transient transfections and chromatin immunoprecipitation assays. Activation of the IGF-IR signaling pathway was evaluated by measuring phosphorylation of ERK, and apoptosis was assayed using poly (ADP-ribose) polymerase cleavage and annexin V-FITC staining. Results obtained showed that folic acid induced a dose-dependent decrease in IGF-IR protein and mRNA levels in the HCT116 +/+ colon cancer cell line. This effect was associated with a significant reduction in IGF-IR promoter activity. Similar effects were elicited by the folic acid metabolites dihydrofolic acid and tetrahydrofolic acid. In addition, folic acid abrogated the IGF-I-stimulated phosphorylation of the downstream signaling molecule ERK1/2 and exhibited a pro-apoptotic activity. Moreover, folic acid induced a significant decrease in Sp1 binding to the IGF-IR promoter region. Finally, folic acid had no effect in wild-type p53-depleted HCT116 -/and Caco-2 cells. In conclusion, the mechanism of action of folic acid involves regulation of IGF-IR gene expression. The ability of folic acid to downregulate the IGF-I signal transduction pathway may allow the micronutrient to function as a chemopreventive agent. Folic acid deficiency, on the other hand, may lead to increased IGF-IR gene expression, with ensuing pathological activation by endocrine and/or autocrine/paracrine IGF-I.
\end{abstract}

Endocrine-Related Cancer (2006) 13 571-581

\section{Introduction}

Diseases of the colon and rectum have assumed the role of a major public health issue in the Western world. The potential involvement of specific micronutrients in colorectal cancer etiology has been the subject of extensive investigation. Folic acid, a member of the vitamin B family, has emerged in recent years as an important player in the etiology of digestive tract cancers, including tumors of the colorectum, esophagus and stomach (Duthie 1999, Kim 2003). Evidence of both an epidemiological and an experimental nature suggested a chemopreventive role for folic acid in colorectal cancer (Giovannucci 2002). Thus, whereas a folic acid-deficient diet was shown to be associated with an increased risk of colon cancer (Giovannucci et al. 1998, Choi \& Mason 2002), dietary folic acid supplementation provided significant protection against the disease (Lashner et al. 1997). The chemopreventive properties of folic acid may be attributed to: (i) its role in the process of DNA methylation, and (ii) its participation in the synthesis of purines and pyrimidines and, consequently, DNA synthesis and repair (Duthie 1999). Hence, folic acid deficiency may activate the tumorigenic process by altering 
the expression of genes involved in critical cellular functions, including cell cycle control, cell death and DNA repair (Duthie 2001).

The insulin-like growth factor (IGF) system plays a critical role in growth and development of many tissues and is also thought to play a prominent role in tumorigenesis. IGF-I and IGF-II are potent mitogenic hormones that are mainly produced in the liver, although malignantly transformed colon cancer cells express significant levels of both ligands. Increased serum levels of IGF-I were recently found to be associated with increased occurrence of adenomatous polyps and even advanced adenomas. In addition, colon cancer cells express high levels of IGF-I receptor (IGF-IR), a tyrosine kinase-containing transmembrane receptor coupled to several intracellular second messenger pathways, including the ras-raf-MAPK and phosphatidylinositol 3-kinase-protein kinase B/Akt signaling cascades (LeRoith et al. 1995, Werner \& LeRoith 1996, Sekharam et al. 2003). The central role of IGF-IR in colon cancer biology is illustrated by the results of experiments showing that IGF-IR blockade inhibited tumor growth and angiogenesis and, furthermore, enhanced chemotherapy-induced apoptosis (Adachi et al. 2002, Reinmuth et al. 2002). However, the transcriptional mechanisms and transcription factors that are directly responsible for IGF-IR overexpression in colorectal cancer cells have not yet been identified.

Owing to the fundamental role of IGF-IR action in colon cancer development, and in view of the chemopreventive function of folic acid, we hypothesized that folic acid may modulate proliferative processes via mechanism/s that involve regulation of IGF-IR gene expression. Results obtained show that folic acid downregulates IGF-IR promoter activity as well as endogenous IGF-IR mRNA and protein levels in a dose-dependent manner. Furthermore, the mechanism of action of folic acid involves inhibition of Spl binding to cis-elements in the proximal IGF-IR promoter region. In addition, folic acid inhibits the IGF-I-induced phosphorylation of downstream mediators, including the signaling molecule ERK, and exhibits a pro-apoptotic activity. Folic acid had no effect on IGF-IR gene expression in cells with a disrupted p53. Combined, our data suggest that the IGF-IR gene is a novel downstream target for folic acid action. The chemopreventive function of folic acid may be linked to its ability to downregulate the IGF-IR signaling pathway. Folic acid deficiency, on the other hand, may lead to aberrant IGF-IR gene expression and enhanced receptor activation by locally produced and/or circulating IGF-I.

\section{Materials and methods}

\section{Cell cultures}

Human colorectal cancer cell lines HCT116 +/+, which expresses wild-type p53, and HCT116 -/-, in which the $\mathrm{p} 53$ gene has been disrupted by targeted homologous recombination, were grown in RPMI1640 medium supplemented with $10 \%$ fetal bovine serum (FBS), $2 \mathrm{mM}$ glutamine and $50 \mu \mathrm{g} / \mathrm{ml}$ gentamicin sulfate. HCT116 cells were provided by $\mathrm{Dr}$ Bert Vogelstein (Johns Hopkins University School of Medicine, Baltimore, MD,USA) (Bunz et al. 1998). The human colon cancer cell line Caco-2 was obtained from the American Type Culture Collection (Manassas, VA, USA). Caco-2 cells were maintained in RPMI-1640 medium containing $10 \%$ FBS.

\section{Western blot analysis}

Cells were serum-starved overnight, after which they were treated with increasing concentrations of folic acid. After $24 \mathrm{~h}$, cells were harvested with ice-cold PBS containing $5 \mathrm{mM}$ EDTA and lysed in a buffer composed of $150 \mathrm{mM} \mathrm{NaCl}, 20 \mathrm{mM}$ Hepes, $\mathrm{pH} 7.5$, $1 \%$ Triton $\mathrm{X}-100,2 \mathrm{mM}$ EDTA, $2 \mathrm{mM}$ EGTA, $1 \mathrm{mM}$ polymethylsulfonyl fluoride, $2 \mu \mathrm{g} / \mathrm{ml}$ aprotinin, $1 \mathrm{mM}$ leupeptin, $1 \mathrm{mM}$ pyrophosphate, $1 \mathrm{mM}$ vanadate and $1 \mathrm{mM}$ dithiothreitol. Samples $(80 \mu \mathrm{g}$ protein) were subjected to $10 \%$ SDS-PAGE, followed by electrophoretic transfer of the proteins to nitrocellulose membranes. Membranes were blocked with $3 \%$ milk in T-TBS $(20 \mathrm{mM}$ Tris- $\mathrm{HCl}, \mathrm{pH} 7.5$, $135 \mathrm{mM} \mathrm{NaCl}$, and $0.1 \%$ Tween-20) and then incubated with an anti-human IGF-IR $\beta$-subunit antibody (C20; Santa Cruz Biotechnology, Santa Cruz, CA, USA). Membranes were washed extensively with T-TBS, and incubated with horseradish peroxidase (HRP)-conjugated secondary antibody. Proteins were detected using the SuperSignalWest Pico Chemiluminescent Substrate (Pierce). In addition, blots were probed with antibodies against total ERK, phospho-ERK1/2 $\left(\mathrm{Thr}^{202} / \mathrm{Tyr}^{204}\right)$ and tubulin.

\section{RT-PCR}

Total RNA was prepared from IGF-I-treated cultures using the AquaPure RNA isolation kit (Bio-Rad). IGF-IR mRNA levels were measured 
by semiquantitative RT-PCR, using the following primers: sense, 5'-TGGAGTGCTGTATGCCTCTG-3'; antisense, 5'-TGATGACCAGTGTTGGCTGG-3' (Lighten et al. 1997). The size of the amplified IGF-IR mRNA fragment was $329 \mathrm{bp}$. For control purposes, levels of glyceraldehyde 3-phosphate dehydrogenase (GAPDH) mRNA were measured using the following primers: sense, 5'-ACCACAGTCCATGCCATCAC-3'; antisense, 5'-TCCACCACCCTGTTGCTGTA-3' (Chen et al. 2004). The size of the amplified GAPDH mRNA fragment was $452 \mathrm{bp}$.

\section{Quantitative real-time PCR}

Quantitative real-time PCR was performed using TaqMan Universal PCR MasterMix and Assayon-Demand Gene Expression primers and probes (Hs00609566_M1) (Applied Biosystems). An ABI Prism $7000^{-}$Sequence Detection System was employed. The GAPDH mRNA levels were analyzed as an internal control and used to normalize IGF-IR mRNA values. Amplification was carried out after an incubation of $2 \mathrm{~min}$ at $50^{\circ} \mathrm{C}$ and $10 \mathrm{~min}$ at $95^{\circ} \mathrm{C}$, followed by 40 cycles at $95^{\circ} \mathrm{C}$ for $15 \mathrm{~s}$ and at $60^{\circ} \mathrm{C}$ for $1 \mathrm{~min}$. The number of PCR cycles to reach the fluorescence threshold was the cycle threshold $\left(\mathrm{C}_{\mathrm{t}}\right)$. Each cDNA sample was tested in triplicate and mean $\mathrm{C}_{\mathrm{t}}$ values are reported. Furthermore, for each reaction, a 'no template' sample was included as a negative control. The relative expression of each mRNA was calculated by $\Delta \mathrm{C}_{\mathrm{t}}$ (where $\Delta \mathrm{C}_{\mathrm{t}}$ is the value obtained by subtracting the $\mathrm{C}_{\mathrm{t}}$ value of GAPDH mRNA from the $\mathrm{C}_{\mathrm{t}}$ value of the target mRNA). $\Delta \Delta \mathrm{C}_{\mathrm{t}}=\left(\Delta \mathrm{C}_{\mathrm{t}}\right.$ of treated sample $-\Delta \mathrm{C}_{\mathrm{t}}$ of control). The relative quantification was determined by standard $2^{-\left(\Delta \Delta \mathrm{C}_{\mathrm{t}}\right)}$ calculations.

\section{Plasmids and DNA transfections}

Transient transfection experiments were performed using an IGF-IR promoter-luciferase reporter plasmid extending from nucleotide (nt) -476 to +640 $(\mathrm{p}(-476 /+640)$ LUC; $\mathrm{nt}+1$ corresponds to the transcription initiation site). The basal promoter activity of this fragment, containing most of the proximal IGF-IR promoter region, has been previously described (Werner et al. 1992, 1994). Transient transfections were also performed using deleted reporter constructs that include 188 or $40 \mathrm{bp}$ of the IGF-IR $5^{\prime}$-flanking region $(\mathrm{p}(-188 /+640) \mathrm{LUC}$ and $\mathrm{p}(-40 /$ +640 )LUC respectively). HCT116 cells were transfected with $1 \mu \mathrm{g}$ of the IGF-IR promoter-reporter plasmid, along with $0.2 \mu \mathrm{g}$ of a $\beta$-galactosidase plasmid ( $\mathrm{pCMV} \beta$ ), using the Metafectene reagent (Biontex Laboratories GmbH, Munich, Germany). Twenty-four hours after transfection, folic acid was added to the medium and cells were harvested after an additional $24 \mathrm{~h}$. In some experiments, increasing doses of the folic acid metabolites dihydrofolic acid and tetrahydrofolic acid were added to the cultures. Luciferase and $\beta$-galactosidase activities were measured as previously described (Werner et al. 1992).

\section{Chromatin immunoprecipitation (ChIP) analysis}

Folic acid-treated cultures were incubated with formaldehyde ( $1 \%$ final concentration) for $10 \mathrm{~min}$ at room temperature. At the end of the incubation period, cells were washed twice and harvested using ice-cold PBS. Pelleted cells were resuspended in a $1 \%$ SDS-containing buffer, incubated on ice for $10 \mathrm{~min}$, and sonicated for $3 \mathrm{~min}$. Cell extracts were then immunoprecipitated with anti-Sp1 antibody for $18 \mathrm{~h}$ at $4{ }^{\circ} \mathrm{C}$. For PCR analysis of Spl-immunoprecipitated chromatin, a set of primers encompassing the proximal human IGF-IR promoter ( $\mathrm{nt}-486$ to +287) was employed (Cooke et al. 1991). Sequencing and DNaseI footprinting analyses revealed the presence of four cis-elements for transcription factor $\mathrm{Sp} 1$ in this particular region (BeitnerJohnson et al. 1995). PCR was performed using the Thermal Ace DNA polymerase kit (InVitrogen).

\section{Apoptosis measurements}

HCT116 +/+ cells were serum-starved for $24 \mathrm{~h}$, after which they were treated with increasing concentrations of folic acid $(0,10,50$ and $100 \mu \mathrm{g} / \mathrm{ml})$, in the absence or presence of IGF-I $(50 \mathrm{ng} / \mathrm{ml})$. Cells $\left(1 \times 10^{6}\right)$ were washed in ice-cold PBS and resuspended in binding buffer (Annexin V-FITC kit; Bender Med Systems $\mathrm{GmbH}$, Vienna, Austria). Annexin V-fluorescein isothiocyanate (FITC) was added to the cell suspension and incubated for $10 \mathrm{~min}$ in the dark. Propidium iodide (PI) was then added and stained cells were analyzed using a FACSort Flow Cytometer (Beckton Dickinson). Viable cells are primarily Annexin V-FITC- and PI-negative; PI-positive staining indicates necrosis, Annexin V-FITC-positive staining indicates early apoptosis, and cells that are Annexin V-FITC- and PI-positive are considered to be in late apoptosis. Folic acid-induced apoptosis was also evaluated by western immunoblotting using a poly (ADP-ribose) polymerase (PARP) antibody (Cell Signaling Technology). 


\section{Results}

IGF-IR overexpression is a typical hallmark of most types of cancer, including colorectal neoplasms. Because folic acid is a nutritional factor whose depletion has been associated with an increased risk for colorectal cancer development, we investigated the potential participation of this nutrient in the regulation of IGF-IR gene expression. Human colon cancer-derived HCT116 +/+ cells were serumstarved overnight and then incubated with increasing concentrations of folic acid for $24 \mathrm{~h}$. Western blot analysis using an anti-IGF-IR $\beta$-subunit antibody revealed that folic acid induced a dose-dependent decrease in endogenous IGF-IR levels. Maximal inhibition $(56.5 \pm 6.5 \%$ of control) was seen at a folic acid dose of $100 \mu \mathrm{g} / \mathrm{ml}$ whereas no change was seen in the levels of tubulin (Fig. 1A and B). To
A

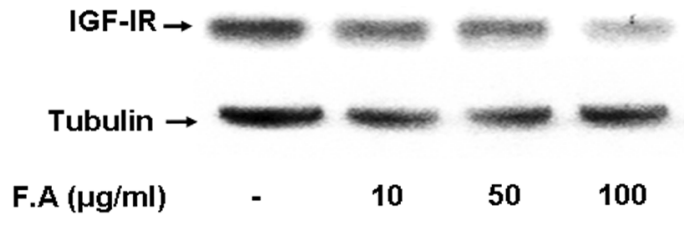

C

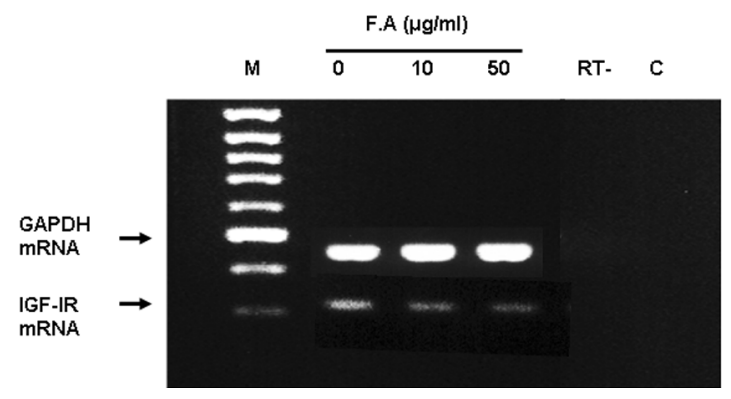

E

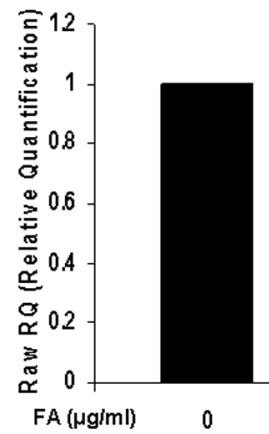

B

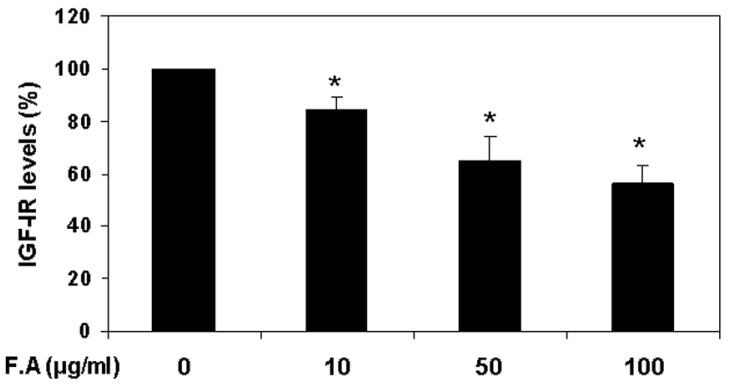

D

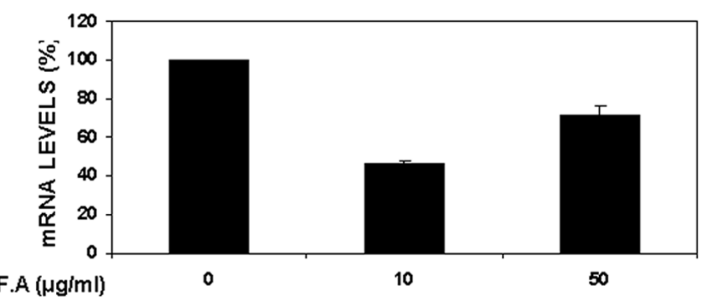

Figure 1 Regulation of IGF-IR gene expression by folic acid (F.A). (A) Serum-starved HCT116 +/+ cells were incubated with increasing doses of folic acid for $24 \mathrm{~h}$. At the end of the incubation period cells were collected as described in Materials and methods and equal amounts of protein $(80 \mu \mathrm{g})$ were separated by $10 \%$ SDS-PAGE and transferred onto nitrocellulose membranes. IGF-IR levels were determined using a polyclonal IGF-IR antibody, followed by incubation with an HRP-conjugated secondary antibody. The position of the $97 \mathrm{kDa}$ IGF-IR $\beta$-subunit is indicated. Membranes were re-probed with a tubulin antibody. The figure shows the result of a typical experiment, repeated four times. (B) Bands corresponding to IGF-IR and tubulin were quantified using scanning densitometry and the optical density was expressed as IGF-IR values normalized to tubulin. A value of $100 \%$ was given to the IGF-IR/tubulin level in untreated cells. The bars represent means \pm S.E.M. of four independent experiments. ${ }^{*} P<0.01$ vs control cells. (C) HCT116 +/+ cells were treated with folic acid $(10-50 \mu \mathrm{g} / \mathrm{ml})$ for $24 \mathrm{~h}$, or left untreated, after which total RNA was prepared and IGF-IR and GAPDH mRNA levels were measured by semiquantitative RT-PCR. 'M', molecular weight marker; 'RT-', control reaction in the absence of reverse transcriptase; 'C', control reaction in the absence of cDNA. (D) Scanning densitometry of IGF-IR mRNA levels normalized to GAPDH mRNA levels. Bars are means \pm S.E.M. of three experiments. (E) Quantitative real-time PCR of IGF-IR mRNA levels in folic acid-treated HCT116 +/+ cells. Cells were treated with increasing doses of folic acid, after which total RNA was prepared and IGF-IR mRNA and GAPDH mRNA values were measured using the TaqMan Real-time PCR system. Analysis of the data was performed as described under Materials and methods. ${ }^{*} P<0.01$ vs control cells. 
A

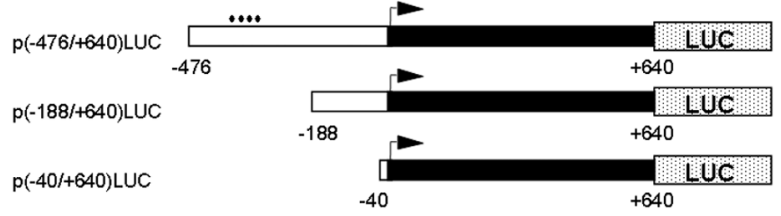

C

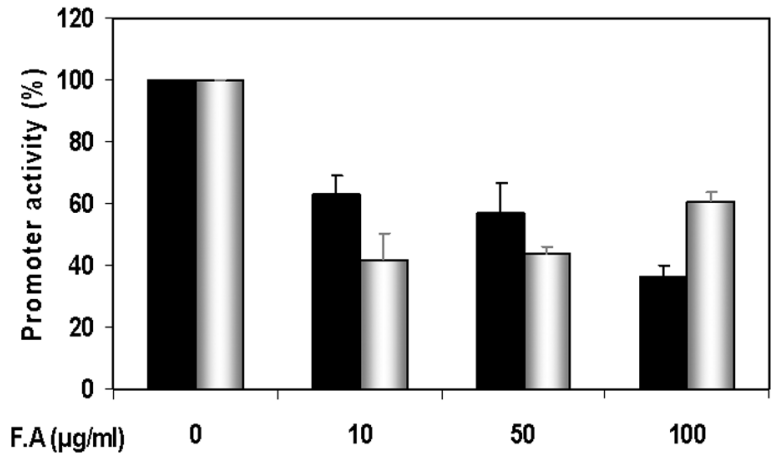

B

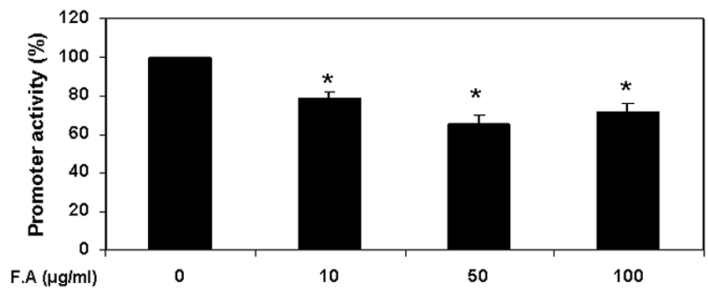

D

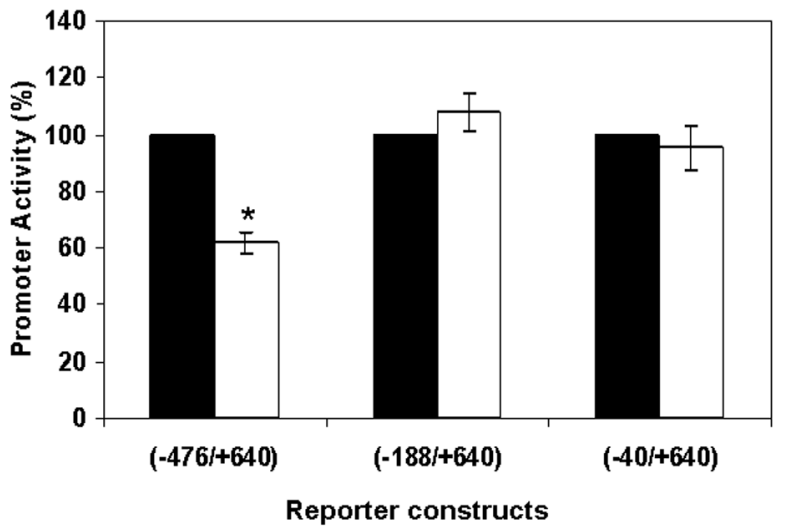

Figure 2 Regulation of IGF-IR promoter activity by folic acid (F.A). (A) Schematic representation of IGF-IR promoter-reporter constructs. Plasmids $p(-476 /+640) L U C, p(-188 /+640)$ LUC and $p(-40 /+640)$ LUC contain, respectively, 476, 188 and 40 bp of $5^{\prime}$-flanking region (open bar) and $640 \mathrm{bp}$ of $5^{\prime}$-untranslated region (closed bar) of the IGF-IR gene, fused to a luciferase cDNA (LUC). An arrow denotes the transcription 'initiator' element. The luciferase cDNA is not shown to scale. Triangles denote a cluster of four Sp1 sites. (B) HCT116 +/+ cells were transfected with $1 \mu \mathrm{g}$ of the $p(-476 /+640)$ LUC IGF-IR promoter-luciferase reporter construct, along with $0.2 \mu \mathrm{g}$ of the $\mathrm{pCMV} \beta$ plasmid, using Metafectene reagent. Twenty-four hours after transfection, folic acid $(0,10,50$ or $100 \mu \mathrm{g} / \mathrm{ml})$ was added to the cultures and cells were incubated for an additional $24 \mathrm{~h}$, after which they were harvested and the levels of luciferase and $\beta$-galactosidase were measured. Promoter activities are expressed as luciferase values normalized for $\beta$-galactosidase levels. A value of $100 \%$ was given to the promoter activity in the absence of folic acid treatment. Results are means \pm S.E.M. of four independent experiments, performed in duplicate dishes. ${ }^{*} P<0.01$ vs untreated cells. (C) Cells were transfected as indicated above and, after $24 \mathrm{~h}$, increasing doses of dihydrofolic acid (open bars) or tetrahydrofolic acid (solid bars) were added to the culture medium. Cells were lysed after an additional $24 \mathrm{~h}$. Results are means \pm S.E.M. of three experiments, performed in duplicate plates. (D) HCT116 $+/+$ cells were transfected with $1 \mu \mathrm{g}$ of the $p(-476 /+640)$ LUC reporter construct or IGF-IR-deleted plasmids ( $p(-188 /+640)$ LUC or $p(-40 /+640)$ LUC) and $0.2 \mu g$ of the pCMV $\beta$ plasmid. Transfected cells were incubated with folic acid (50 $\mu \mathrm{g} / \mathrm{ml})$ (open bars), or left untreated (solid bars) and processed as described above. A value of $100 \%$ was given to the basal activity of each reporter construct in the absence of folic acid. ${ }^{*} P<0.01$ vs controls.

establish whether the inhibitory effect of folic acid was associated with a corresponding reduction in IGF-IR mRNA levels, HCT116 +/+ cells were treated with folic acid for $24 \mathrm{~h}$, after which IGF-IR mRNA levels were measured by semiquantitative RT-PCR. Results obtained showed that folic acid induced a significant decrease in IGF-IR steady-state mRNA levels $(50.0 \pm 1.5 \%$ of control at $10 \mu \mathrm{g} / \mathrm{ml}$ folic acid and $46.2 \pm 5.7 \%$ at $50 \mu \mathrm{g} / \mathrm{ml}$ ) (Fig. $1 \mathrm{C}$ and D). No change was seen in GAPDH mRNA levels. These results were corroborated by TaqMan real-time PCR. As shown in Fig. 1E, folic acid $(50 \mu \mathrm{g} / \mathrm{ml})$ induced a $40 \%$ reduction in IGF-IR mRNA values, while at $10 \mu \mathrm{g} / \mathrm{ml}$ there was a $10 \%$ inhibition. Further- more, TaqMan analyses showed no reduction in IGF-IR mRNA levels at short incubation times (2-4h) (data not shown).

To determine whether the effect of folic acid on IGF-IR gene expression was mediated at the level of transcription of the IGF-IR gene, transient transfection experiments were performed in HCT116 +/+ cells using a luciferase reporter construct under the control of the proximal IGF-IR promoter ( $p(-476 /+640)$ LUC) (Fig. 2A). Twenty-four hours after transfection, increasing doses of folic acid were added to the cells and, after an additional $24 \mathrm{~h}$, cells were collected and promoter activity was measured. Results obtained indicated that folic 
acid repressed IGF-IR promoter activity, with maximal suppression achieved at a concentration of $50 \mu \mathrm{g} / \mathrm{ml}(66 \pm 4.3 \%$ of control untreated cells $)$ (Fig. 2B). Similar decreases in luciferase activity were elicited by the folic acid metabolites dihydrofolic acid and tetrahydrofolic acid (Fig. 2C). To more accurately map the IGF-IR promoter region responsible for mediating the effect of folic acid, transfections were performed using the deleted reporter plasmids $\mathrm{p}(-188 /+640) \mathrm{LUC}$ and $\mathrm{p}(-40 /$ +640)LUC. Construct $p(-188 /+640)$ LUC lacks a cluster of four Sp1 sites between nt -399 and -331 that appears to mediate the majority of $\mathrm{Sp} 1$ activation of the promoter. Construct $\mathrm{p}(-40 /+640) \mathrm{LUC}$ includes a minimal $5^{\prime}$-flanking sequence composed of $40 \mathrm{bp}$ located immediately upstream of the 'initiator' element (Beitner-Johnson et al. 1995). The ability of folic acid to inhibit IGF-IR promoter activity was abrogated in the $\mathrm{p}(-188 /+640) \mathrm{LUC}$ and $\mathrm{p}(-40 /+640) \mathrm{LUC}$ reporter plasmids in comparison with $\mathrm{p}(-476 /+640) \mathrm{LUC}$ (Fig. 2D).

Spl was previously identified as a zinc-finger nuclear protein which plays a crucial role in IGFIR gene transactivation. To examine whether folic acid treatment may lead to reduced $\mathrm{Sp} 1$ binding to cis-elements in the IGF-IR promoter region, ChIP experiments were performed using folic acidtreated HCT116 +/+ cells (or control untreated cells). At the end of the 24-h incubation period, cell lysates were immunoprecipitated with anti-Sp1, after which precipitated chromatin was amplified by PCR using primers encompassing the proximal human IGF-IR promoter. Results of ChIP assays showed that folic acid $(50 \mu \mathrm{g} / \mathrm{ml})$ induced a noticeable decrease in $\mathrm{Sp} 1$ binding to the IGF-IR promoter (Fig. 3).

To examine whether folic acid can modulate early IGF-I-mediated signal transduction events, HCT116 $+/+$ cells were incubated for $24 \mathrm{~h}$ in the absence or presence of folic acid $(10 \mu \mathrm{g} / \mathrm{ml})$ and then treated with IGF-I (50 ng/ml) for 20 or $40 \mathrm{~min}$. Phosphorylation of the downstream signaling molecule ERK was assessed using a specific anti-phospho-ERK1/ 2. As shown in Fig. 4, folic acid treatment abrogated the IGF-I-stimulated ERK1/2 phosphorylation at both 20 and $40 \mathrm{~min}$, although results reached statistical significance only at $20 \mathrm{~min}$ of IGF-I treatment $(P<0.01$ vs IGF-I-treated cells in the absence of folic acid).

Previous studies have established that folic acid inhibits colon cancer cell proliferation and enhances epithelial apoptosis (Jaszewski et al. 1999, Akoglu et al. 2001, 2004, Duthie 2001, Cao et al. 2005). To

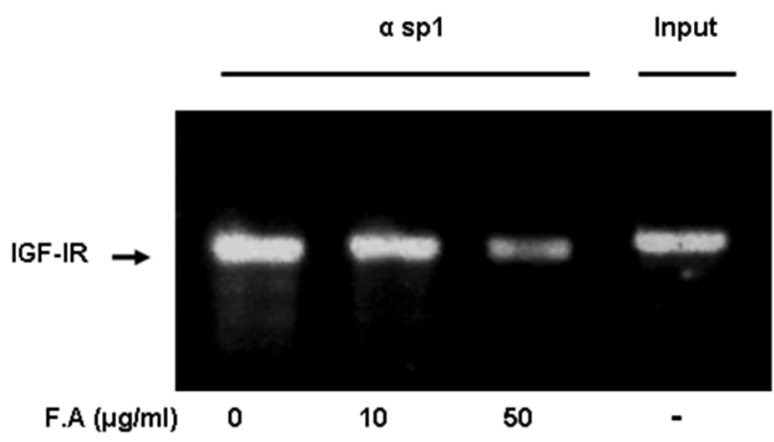

Figure 3 Chromatin immunoprecipitation assay. HCT116 +/+ cells were incubated with increasing doses of folic acid (F.A) for $24 \mathrm{~h}$. After incubation, cells were lysed and immunoprecipitated with an anti-Sp1 antibody ( $\alpha$ sp1), followed by PCR amplification of precipitated chromatin using primers encompassing the human IGF-IR promoter region extending from -486 to +287 . The position of the $773 \mathrm{bp}$ amplified fragment is denoted by the arrow. The input band represents the amplified PCR product in the absence of Sp1 antibody.

A

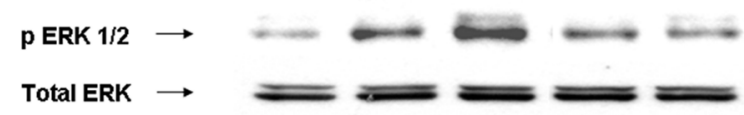

\begin{tabular}{|c|c|c|c|c|c|}
\hline IGF-I (50 ng/ml) 20' & - & + & - & + & - \\
\hline IGF-I (50 ng/ml) 40' & - & - & + & - & + \\
\hline FA $(10 \mu \mathrm{g} / \mathrm{ml})$ & - & - & - & + & + \\
\hline
\end{tabular}

B

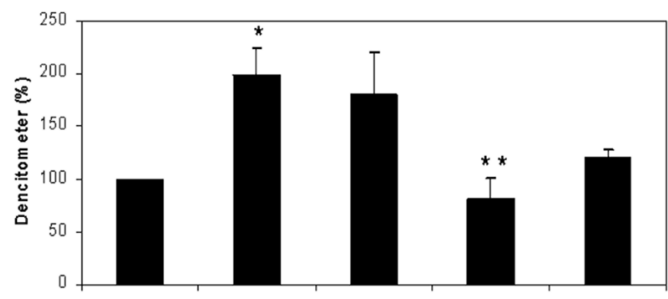

\begin{tabular}{|c|c|c|c|c|c|}
\hline IGF-I $(50 \mathrm{ng} / \mathrm{ml}) 20^{\circ}$ & - & + & - & + & - \\
\hline IGF-I $(50 \mathrm{ng} / \mathrm{ml}) 40^{\circ}$ & - & - & + & - & + \\
\hline FA $(10 \mathrm{\mu g} / \mathrm{ml})$ & - & - & - & + & + \\
\hline
\end{tabular}

Figure 4 Effect of folic acid (F.A) on IGF-I-stimulated signal transduction. (A) HCT116 +/+ cells were incubated with folic acid $(10 \mu \mathrm{g} / \mathrm{ml})$ for $24 \mathrm{~h}$ (or left untreated) and then treated with IGF-I $(50 \mathrm{ng} / \mathrm{ml})$ for 20 or $40 \mathrm{~min}$. Cell lysates were electrophoresed, transferred to membranes, and probed with antibodies against phospho (p)-ERK1/2 and total ERK1/2. (B) The bar graph denotes the densitometric scanning of the phospho-ERK1/2 bands normalized to the corresponding total ERK $1 / 2$ band. The bars represent the means \pm S.E.M. of three independent experiments. ${ }^{*} P<0.05$ vs unstimulated cells (lanes 2 vs 1 ); ${ }^{* *} P<0.05$ vs IGF-I-treated cells (lanes 4 vs 2 ). 


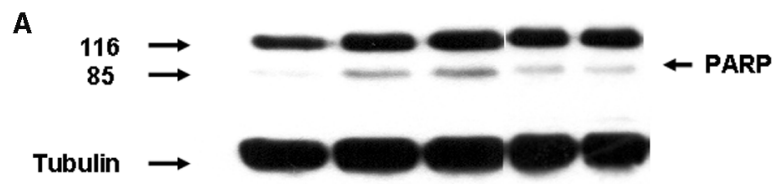

\begin{tabular}{|llllll|}
\hline F.A $(\mu \mathrm{g} / \mathrm{ml})$ & - & 50 & 100 & 50 & 100 \\
IGF-I $(50 \mathrm{ng} / \mathrm{ml})$ & - & - & - & + & + \\
\hline
\end{tabular}

$\mathbf{B}$
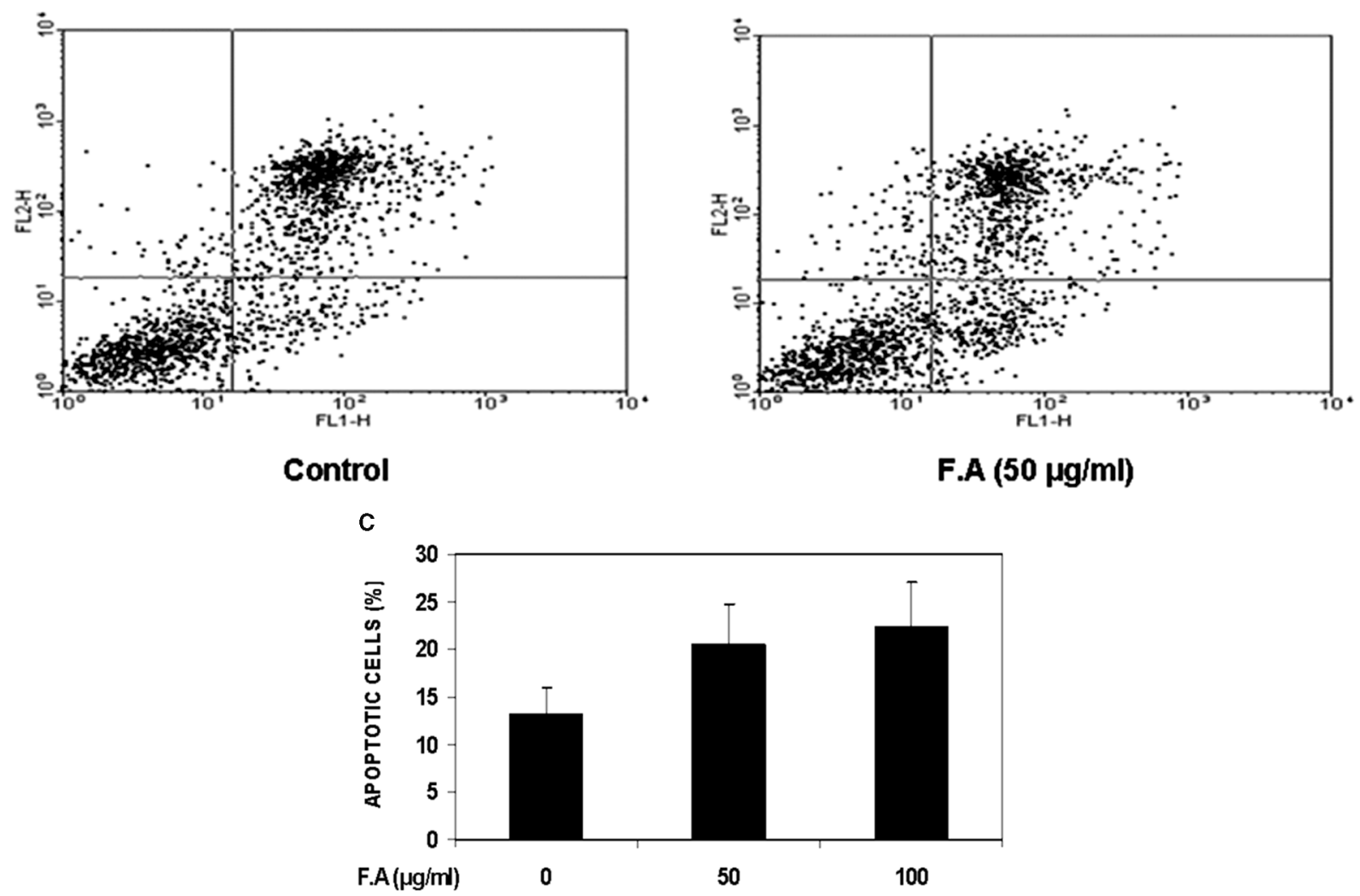

Figure 5 Analyses of the effect of folic acid (F.A) on apoptosis. (A) Serum-starved HCT116 +/+ cells were treated with folic acid $(50-100 \mu \mathrm{g} / \mathrm{ml}$ ) for $24 \mathrm{~h}$ (or left untreated, lane 1), in the absence (lanes 2 and 3) or presence (lanes 4 and 5) of IGF-I (50 ng/ml) during the last $1 \mathrm{~h}$ of the incubation period. Apoptosis was evaluated by western blotting using anti-PARP. Membranes were re-probed with a tubulin antibody. (B) Apoptosis was assessed in folic acid-treated and control HCT116 $+/+$ cultures using an Annexin-FITC kit, as described in Materials and methods. The horizontal axis denotes 'Annexin V-FITC positive cells' and the vertical axis represents 'PI positive cells'. Results of a representative experiment repeated three times are shown. (C) Quantitative analysis of the flow cytometry data was performed using WinMDI 2.8 software (http://facs.scripps.edu/software.html).

examine whether folic acid exhibits a pro-apoptotic activity under our experimental conditions, HCT116 +/+ cells were serum-starved overnight, after which they were incubated with folic acid $(50-100 \mu \mathrm{g} / \mathrm{ml})$ for $24 \mathrm{~h}$ and apoptosis was evaluated by Western blotting using an anti-PARP antibody. As shown in Fig. 5A, lanes 2 and 3, folic acid induced the appearance of an $\sim 85 \mathrm{kDa}$ protein, which represents a cleavage product of the $\sim 116 \mathrm{kDa}$ PARP protein, and which is considered a marker of early apoptosis. These results were corroborated using an Annexin V-FITC kit. Results of FACS analysis showed that folic acid enhanced apoptosis in a dose-dependent fashion $(20.5 \pm 3.1 \%$ apoptotic cells at $50 \mu \mathrm{g} / \mathrm{ml}$ folic acid and $22.3 \pm 4.2 \%$ apoptotic cells at $100 \mu \mathrm{g} / \mathrm{ml}$, compared with $13.2 \pm 2.4 \%$ apoptotic cells in control cultures) (Fig. 5B and C). To determine whether IGF-I can abolish the pro-apoptotic action of folic acid, cells were incubated with folic acid in the 
presence of IGF-I $(50 \mathrm{ng} / \mathrm{ml}, 1 \mathrm{~h})$, after which apoptosis was measured. Western blotting of PARP protein revealed that the intensity of the $85 \mathrm{kDa}$ band was significantly diminished in cells that were treated with both IGF-I and folic acid, compared with cells treated only with folic acid (Fig. 5A, compare lanes 4 vs 2 and 5 vs 3 ).

Finally, to examine the potential contribution of p53 status to folic acid action, IGF-IR levels were measured in folic acid-treated HCT116 - / - cells, in which the p53 gene has been disrupted by homologous recombination. The rationale for this experiment was the fact that folic acid has been recently shown to enhance p53 expression in gastric mucosa (Cao et al. 2005), suggesting that p53 may mediate the inhibitory action of folic acid. Results of western immunoblots showed that folic

A

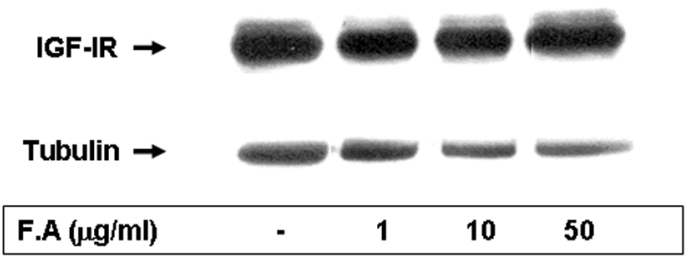

B

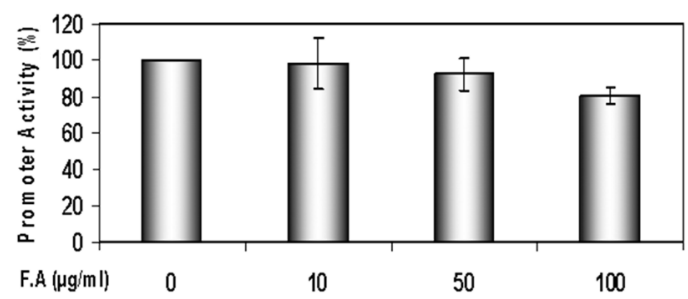

C

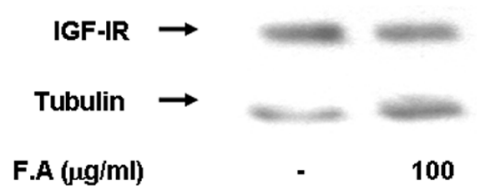

Figure 6 Effect of p53 status on folic acid (F.A) action. (A) p53-depleted HCT116 -/- cells were serum-starved overnight, after which they were treated with increasing concentrations of folic acid for $24 \mathrm{~h}$. IGF-IR abundance was assessed by western immunoblotting as indicated in Materials and methods. (B) HCT116 -/- cells were transfected with $1 \mu \mathrm{g}$ of the $\mathrm{p}(-476 /+640)$ LUC IGF-IR promoter-luciferase reporter construct, along with $0.2 \mu \mathrm{g}$ of $p C M V \beta$. After $24 \mathrm{~h}$, folic acid $(0,10,50$ or $100 \mu \mathrm{g} / \mathrm{ml})$ was added to the cultures and cells were incubated for an additional $24 \mathrm{~h}$. Cells were harvested and luciferase and $\beta$-galactosidase activities were determined. Results are means \pm S.E.M. of three independent experiments. (C) Serum-starved Caco-2 cells were treated with folic acid for $24 \mathrm{~h}$ and IGF-IR levels were measured by western blotting as described above. acid had no effect on IGF-IR levels in p53-depleted HCT116 -/- cells (Fig. 6A). Moreover, folic acid had no major effect on IGF-IR promoter activity in HCT116 -/- cells (Fig. 6B). Likewise, we were unable to see a folic acid-induced decrease in IGF-IR levels in the human colon cancer cell line Caco-2, which includes a mutant p53 allele (Fig. 6C). Finally, we were unable to detect an increase in p53 levels in folic acid-treated HCT116 +/+ cells (data not shown).

\section{Discussion}

The important role of the IGF system in colon cancer has been firmly established. Circulating IGF-I levels were shown to control the incidence of tumor development and hepatic metastasis in a mouse model of colon cancer as well as the incidence of adenomatous polyps in humans (Wu et al. 2002). IGF-IR, which mediates the anti-apoptotic activity of the IGF ligands, is abundantly expressed in colon cancer cells. Furthermore, specific blockade of IGF-IR was shown to be associated with inhibition of tumor growth and angiogenesis, and with enhanced chemotherapy-induced apoptosis (Adachi et al. 2002, Reinmuth et al. 2002). While nutritional status has a profound impact on IGF-IR gene expression and action, the contribution of specific micronutrients has not yet been explored in a systematic manner. Folic acid, a water-soluble member of the vitamin B family found in fruits and green leafy vegetables, exhibits a chemoprotective action that has been linked to its capacity to affect DNA methylation and/or normal DNA synthesis and repair. Poor folate intake may lead to inappropriate proto-oncogene activation, aberrant DNA repair, and chromosomal damage (Duthie 1999). We chose therefore to test the hypothesis that folic acid may act through modulation of IGF-IR gene expression.

The results presented here demonstrate that physiological concentrations of folic acid induced a dose-dependent decrease in endogenous IGF-IR protein and mRNA levels (Fig. 1), suggesting that the IGF-IR gene is a relevant target for folic acid action. Furthermore, the inhibitory action of folic acid and two of its metabolites is mediated at the transcriptional level, as demonstrated by the results of transient transfection experiments (Fig. 2). Molecular characterization of the IGF-IR gene regulatory region revealed that the IGF-IR promoter includes a unique initiator motif from which transcription starts in vivo and, similarly to other growth factor 
receptor-encoding genes, contains multiple binding sites (GC boxes) for members of the $\mathrm{Sp} 1$ family of zinc-finger transcription factors (Courey \& Tjian 1988, Werner et al. 1992, Beitner-Johnson et al. 1995). Results of ChIP experiments presented here suggest that a potentially novel mechanism of action of folic acid may involve a decrease in Sp1 binding to cis-elements in the proximal IGF-IR promoter region. Reduction in $\mathrm{Sp} 1$ binding has been previously shown to lead to diminished IGF-IR gene transcription (Abramovitch et al. 2003). The finding that folic acid abrogated the IGF-I-stimulated increase in ERK phosphorylation may be consistent with the possibility that folic acid controls IGF-IR levels and IGF-IR action at both transcriptional and post-transcriptional levels. Recent studies showed that folic acid increased IGF-binding protein-3 (IGFBP-3) levels in several cervical cancer cell lines. These results suggest that folic acid may modulate IGF action by concomitant inhibition of the anti-apoptotic IGF-IR gene and stimulation of the pro-apoptotic IGFBP-3 gene (Mathur \& Mathur 2003).

A recent study has shown that folic acid and its metabolites inhibit basal and serum-stimulated epidermal growth factor receptor (EGFR) promoter activity (Nagothu et al. 2004). In contrast to our results, the repression of the EGFR promoter by folic acid seems to be Sp1-independent as Sp1deleted EGFR reporter constructs were inhibited by folic acid to a similar extent as the wild-type reporter. Furthermore, the fact that 5-aza-2'-deoxycytidine (a methylation inhibitor) reversed the effect of folic acid on EGFR promoter activity, suggested that folic acid may repress EGFR gene expression by enhancing promoter methylation. While the IGF-IR gene promoter contains a number of $\mathrm{CpG}$ islands, no study so far has demonstrated methylation of the IGF-IR gene as a potential epigenetic mechanism for gene silencing. Combined, these studies suggest that folic acid exerts a chemopreventive role by governing expression of various growth factor receptor genes via multiple mechanisms of action.

In addition, the results of the present study demonstrate that folic acid repressed IGF-IR gene expression in a p53-dependent manner. Tumor suppressor p53 is a pivotal player in the apoptotic process and it has a major role in the protection of cells from DNA damage. The finding that folic acid was unable to downregulate IGF-IR levels in wild-type p53-depleted cells suggests that an intact p53 signaling pathway is a prerequisite to elicit the pro-apoptotic effect of folic acid. Furthermore, since previous studies have demonstrated that wildtype, but not mutant, p53 suppressed IGF-IR promoter activity, we may speculate that the mechanism of action of folic acid involves stimulation of expression and/or activation of $\mathrm{p} 53$, which can then directly act at the IGF-IR promoter level (Werner et al. 1996). Consistent with this hypothesis, previous studies have demonstrated that folic acid enhances p53 expression in the gastric mucosa (Cao et al. 2005). Unfortunately, we were unable to demonstrate an increase in p53 levels in HCT116 + / + cells following folic acid treatment. Interestingly, recent studies have identified the IGF-IR gene as a downstream target in a DNAdamage response pathway, whereas $\mathrm{Sp} 1$ was shown to mediate the IGF-IR response following ionizing radiation (Shahrabani-Gargir et al. 2004). In view of the important body of evidence indicating that folate deficiency is associated with DNA strand breaks, impaired DNA repair and increased susceptibility to mutagenesis, it is reasonable to suggest that at least part of the pathological spectrum associated with folate depletion may result from aberrant activation of the IGF-IR gene.

In conclusion, we have presented evidence showing that folic acid governs IGF-IR gene expression in colon cancer cells via mechanism/s involving transcriptional suppression of the IGFIR promoter. These results are consistent with the notion that the chemopreventive function of folic acid may be linked to its ability to inhibit IGF-IR levels. Below a certain IGF-IR threshold level, the capacity of most cells to engage in mitogenic activity is significantly impaired (Rubini et al. 1997). Deregulated expression of the IGF-IR gene as a result of deficient folate intake may be associated with genomic instability, defective cell division, impaired checkpoint arrest, and enhanced transforming capacity.

\section{Acknowledgements}

$\mathrm{ZA}$ in the Sackler Faculty of Medicine, Tel Aviv University, Tel Aviv, Israel, performed this work in partial fulfillment of the requirements for an MSc degree. We thank Dr Bert Vogelstein for the HCT116 cell lines. This work was supported by a grant from the Eduarda and Dr Moshe Ishai Institute on Natural Nutrition, Tel Aviv University. The authors declare that there is no conflict of interest that would prejudice the impartiality of this scientific work. 


\section{References}

Abramovitch S, Glaser T, Ouchi T \& Werner H 2003 BRCA1-Sp1 interactions in transcriptional regulation of the IGF-IR gene. FEBS Letters 541 149-154.

Adachi Y, Lee CT, Coffee K, Yamagata N, Ohm JE, Park KH, Dikov MM, Nadaf SR, Arteaga CL \& Carbone DP 2002 Effect of genetic blockade of the insulin-like growth factor receptor in human colon cancer cell lines. Gastroenterology 123 1191-1204.

Akoglu B, Faust D, Milovic V \& Stein J 2001 Folate and chemoprevention of colorectal cancer: is 5-methyltetrahydrofolate an active antiproliferative agent in folate-treated colon cancer cell? Nutrition 17 $652-653$.

Akoglu B, Milovic V, Caspary WF \& Faust D 2004 Hyperproliferation of homocysteine-treated colon cancer cells is reversed by folate and 5-methyltetrahydrofolate. European Journal of Nutrition 43 93-99.

Beitner-Johnson D, Werner H, Roberts CT Jr \& LeRoith D 1995 Regulation of insulin-like growth factor I receptor gene expression by Sp1: physical and functional interactions of Sp1 at GC boxes and at a CT element. Molecular Endocrinology 9 1147-1156.

Bunz F, Dutriaux A, Lengauer C, Waldman T, Zhou S Brown JP, Sedivy JM, Kinzler KW \& Vogelstein B 1998 Requirement for p53 and p21 to sustain G2 arrest after DNA damage. Science 282 1497-1501.

Cao D-Z, Sun W-H, Ou X-L, Yu Q, Yu T, Zhang Y-Z, Wu Z-Y, Xue Q-P \& Cheng Y-L 2005 Effects of folic acid on epithelial apoptosis and expression of Bcl-2 and p53 in premalignant gastric lesions. World Journal of Gastroenterology 11 1571-1576.

Chen AL, Fang C, Liu C, Leslie MP, Chang E \& Di Cesare PE 2004 Expression of bone morphogenetic proteins, receptors, and tissue inhibitors in human fetal, adult, and osteoarthritic articular cartilage. Journal of Orthopaedic Research 22 1188-1192.

Choi SW \& Mason JB 2002 Folate status: effects on pathways of colorectal carcinogenesis. Journal of Nutrition 132 2413S-2418S.

Cooke DW, Bankert LA, Roberts CT Jr, LeRoith D \& Casella SJ 1991 Analysis of the human type I insulin-like growth factor receptor promoter region. Biochemical and Biophysical Research Communications 177 1113-1120.

Courey AJ \& Tjian R 1988 Analysis of Sp1 in vivo reveals multiple transcriptional domains, including a novel glutamine-rich activation motif. Cell 55 887-898.

Duthie SJ 1999 Folic acid deficiency and cancer: mechanisms of DNA instability. British Medical Bulletin 55 578-592.

Duthie SJ 2001 Folic acid-mediated inhibition of human colon cancer cell growth. Nutrition 17 736-737.

Giovannucci E 2002 Epidemiological studies of folate and colorectal neoplasia: a review. Journal of Nutrition 132 2350S-2355S.

Giovannucci E, Stampfer MJ, Colditz GA, Hunter DJ, Fuchs C, Rosner D, Rosner BA, Speitzer FE \& Willet WC
1998 Multivitamin use, folate, and colon cancer in women in the Nurse's Health Study. Annals of Internal Medicine $129517-524$.

Jaszewski R, Khan A \& Sarkar FH 1999 Folic acid inhibition of EGFR-mediated proliferation in human colon cancer cell lines. American Journal of Physiology 277 C1142-C1148.

Kim Y-I 2003 Role of folate in colon cancer development and progression. Journal of Nutrition 133 3731S-3739S.

Lashner BA, Provencher KS, Seidner DL, Knesebeck A \& Brezezinski A 1997 The effect of folic acid supplementation on the risk for cancer or dysplasia in ulcerative colitis. Gastroenterology 112 29-32.

LeRoith D, Werner H, Beitner-Johnson D \& Roberts CT Jr 1995 Molecular and cellular aspects of the insulin-like growth factor I receptor. Endocrine Reviews 16 143-163.

Lighten AD, Hardy K, Winston RM \& Moore GE 1997 Expression of mRNA for the insulin-like growth factors and their receptors in human preimplantation embryos. Molecular Reproduction and Development 47 134- 139.

Mathur RS \& Mathur SP 2003 In vitro downregulation of growth factors by insulin-like growth factor binding protein-3 in cervical cancer. Gynecological Oncology 91 410-415.

Nagothu KK, Rishi AK, Jaszewski R, Kucuk O \& Majumdar APN 2004 Folic acid-mediated inhibition of serum-induced activation of EGFR promoter in colon cancer cells. American Journal of Physiology. Gastrointestinal and Liver Physiology 287 G541-G546.

Reinmuth N, Liu W, Fan F, Jung YD, Ahmad SA, Stoeltzing O, Bucana CD, Radinsky R \& Ellis LM 2002 Blockade of the insulin-like growth factor-I receptor function inhibits growth and angiogenesis of colon cancer. Clinical Cancer Research 8 3259-3269.

Rubini M, Hongo A, D’Ambrosio C \& Baserga R 1997 The IGF-I receptor in mitogenesis and transformation of mouse embryo cells: role of receptor number. Experimental Cell Research 230 284-292.

Sekharam M, Zhao H, Sun M, Fang Q, Zhang Q, Yuan Z, Dan HC, Boulware D, Cheng JQ \& Coppola D 2003 Insulin-like growth factor-I receptor enhances invasion and reduces resistance to apoptosis of colon cancer cells through the Akt/Bcl-x(L) pathway. Cancer Research $\mathbf{6 3}$ 7708-7716.

Shahrabani-Gargir L, Pandita TK \& Werner H 2004 Ataxia-telangiectasia mutated gene controls IGF-IR gene expression in a DNA damage response pathway via mechanisms involving zinc-finger transcription factors $\mathrm{Sp} 1$ and WT1. Endocrinology 145 5679-5687.

Werner H \& LeRoith D 1996 The role of the insulin-like growth factor system in human cancer. Advances in Cancer Research 68 183-223.

Werner H, Bach MA, Stannard B, Roberts CT Jr \& LeRoith D 1992 Structural and functional analysis of the insulin-like growth factor I receptor gene promoter. Molecular Endocrinology 6 1545-1558. 
Werner H, Rauscher FJ III, Sukhatme VP, Drummond IA, Roberts CT Jr \& LeRoith D 1994 Transcriptional repression of the insulin-like growth factor I receptor (IGF-I-R) gene by the tumor suppressor WT1 involves binding to sequences both upstream and downstream of the IGF-I-R gene transcription start site. Journal of Biological Chemistry 269 $12577-12582$.
Werner H, Karnieli E, Rauscher FJ III \& LeRoith D 1996 Wild type and mutant p53 differentially regulate transcription of the insulin-like growth factor I receptor gene. PNAS 93 8318-8323.

Wu Y, Yakar S, Zhao L, Hennighausen L \& LeRoith D 2002 Circulating insulin-like growth factor-I levels regulate colon cancer growth and metastasis. Cancer Research 62 1030-1035. 
